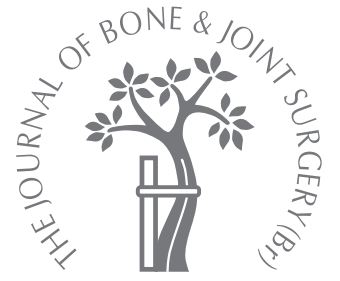

S. Shalaby, H. Shalaby,

A. Bassiony

From the

Orthopaedic

Department, Ain

Shams University,

Cairo, Egypt

\title{
Limb salvage for osteosarcoma of the distal tibia with resection arthrodesis, autogenous fibular graft and Ilizarov external fixator
}

S. Shalaby, MD(Orth), Professor of Orthopaedic Surgery

H. Shalaby, MD(Orth), Lecturer of Orthopaedic Surgery

A. Bassiony, MD(Orth), Lecturer of Orthopaedic Surgery

Ains Shams University Orthopaedic Department, El Demerdash Hospital, Ramse Street, El Abbassia, 11381 , Cairo, Egypt.

Correspondence should be sent to $\mathrm{Dr}$ H. Shalaby; e-mail:

hishamshalaby@yahoo.com

(C)2006 British Editorial Society of Bone and Joint Surgery doi:10.1302/0301-620X.88B12. $17879 \$ 2.00$

$J$ Bone Joint Surg [Br] 2006;88-B:1642-6.

Received 13 March 2006

Accepted after revision 18 July 2006

We report the results of limb salvage for non-metastatic osteosarcoma of the distal tibia using resection arthrodesis, autogenous fibular graft and fixation by an Ilizarov external fixator.

In six patients with primary osteosarcoma of the distal tibia who refused amputation, treatment with wide en bloc resection and tibiotalar arthrodesis was undertaken. The defect was reconstructed using non-vascularised free autogenous fibular strut graft in three patients and a vascularised pedicular fibular graft in three, all supplemented with iliac cancellous graft at the graft-host junction. An Ilizarov external fixator was used for stabilisation of the reconstruction.

In five patients sound fusion occurred at a mean of 13.2 months (8 to 20) with no evidence of local recurrence or deep infection at final follow-up. The mean post-operative functional score was $70 \%$ (63\% to $73 \%$ ) according to the Musculoskeletal Tumour Society scoring system. All five patients showed graft hypertrophy.

Union of the graft was faster in cases reconstructed by vascularised fibular grafts. One patient who had a poor response to pre-operative chemotherapy developed local tumour recurrence at one year post-operatively and required subsequent amputation.

Primary malignant bone tumours of the distal tibia are very rare. ${ }^{1}$ Amputation has been the standard surgical treatment with satisfactory functional results obtained using an appropriate prosthesis. ${ }^{2}$ With advances in limb salvage surgery, reconstruction has been attempted using autograft, allograft, implanted prostheses and composites. When the ankle is involved, limb salvage presents unique difficulties both in terms of the biomechanics and obtaining soft-tissue cover. ${ }^{3}$ Casadei et $\mathrm{al}^{4}$ reported that arthrodesis is the best reconstructive procedure for the ankle in patients for whom limb salvage is indicated.

The aim of this study was to assess the results of treating a group of patients with high grade osteosarcoma of the distal tibia using a specific protocol for limb salvage, of wide en bloc intra-articular excision and reconstruction of the defect with autogenous fibular strut graft, stabilised using an Ilizarov external fixator.

\section{Patients and Methods}

A series of six patients with high grade nonmetastatic primary osteosarcoma of the distal tibia (Fig. 1) who had refused amputation, were treated by wide en bloc excision with reconstruction of the defect by autogenous strut fibular graft with stabilisation provided by an Ilizarov external fixator (Smith \& Nephew, Memphis, Tennessee). Following clinical diagnosis, imaging studies including plain radiographs, MRI, CT scans, bone scans and angiography were carried out to assess tumour mass, soft-tissue involvement, infiltration of adjacent tissues and to determine the margins of resection. Carefully planned open biopsy was undertaken for all patients, with histopathological examination confirming conventional high grade osteosarcoma. All of the tumours were graded as Enneking stage IIB. ${ }^{5}$ Restaging was undertaken after three cycles of pre-operative chemotherapy at three week intervals, each formed of adriamycin $75 \mathrm{mg} / \mathrm{m}^{2}$ and cisplatin in $105 \mathrm{mg} / \mathrm{m}^{2}$ for three days.

The mean age of the patients at the time of surgery was 18.8 years (16 to 23 ). Three patients were male and three female. The mean follow-up was 35 months (28 to 42).

Surgical technique. The operation consisted of three main steps: wide en bloc intra-articular excision, reconstruction of the defect by autogenous fibular strut graft and fixation of the graft using an Ilizarov external fixator. 


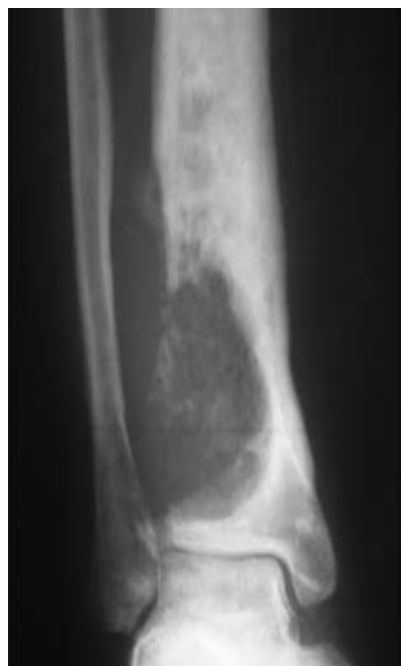

Fig. 1a

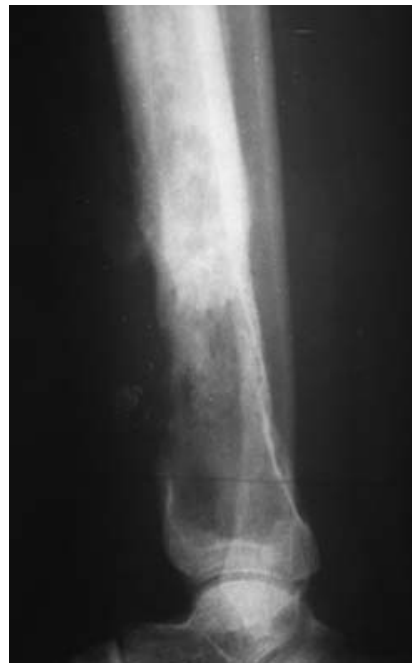

Fig. 1b
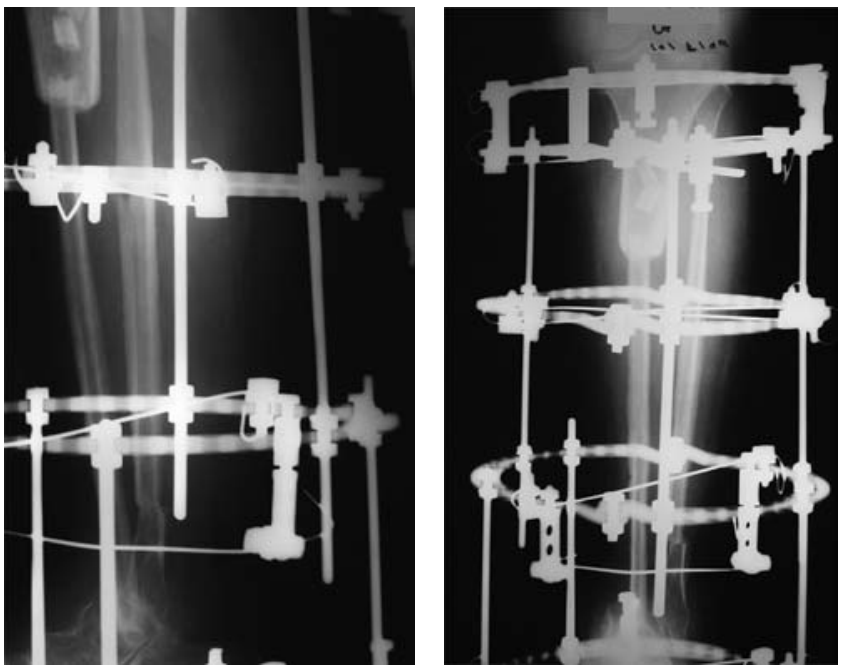

Fig. 2

Radiographs taken at presentation showing an osteolytic lesion of the right distal tibia, from a) anteroposterior and b) lateral views.

The mean length of the bony defect after excision of the tumour segment was $17 \mathrm{~cm}$ (15 to 19). In three patients the fibular graft was taken as a free non-vascularised segment through a lateral approach with subperiosteal dissection. In the others the fibular graft was transferred with its attached muscles and intact nutrient peroneal blood vessels. The mean length of the fibular graft was $19.8 \mathrm{~cm}$ (18 to 22). The fibula was inserted proximally at the tibial osteotomy site into the intramedullary canal and distally into a trough in the talus to achieve tibiotalar fusion. All patients had supplementary iliac crest cancellous bone graft placed around the graft host junctions.

The Ilizarov frame had a proximal partial ring connected to a full ring by three or four connecting rods, a full ring in the middle overlying the fibular graft and a distal foot assembly composed of a calcaneal half ring connected to a forefoot half ring. One or two wires were inserted under direct vision into the fibular graft, tensioned and fixed to the middle full ring to allow manipulation of the graft and compression at both ends during the follow-up period, if needed (Fig. 2).

Post-operatively, all patients were allowed immediate full weight-bearing up to their tolerance.

The degree of tumour necrosis, in response to the preoperative chemotherapy, was rated according to the Huvos grading system. ${ }^{6}$ Three patients had a grade IV response (complete tumour necrosis), two had a grade III response (more than 90\% necrosis) and one had a grade II response (less than $90 \%$ necrosis).

The patients were examined clinically and radiologically every six weeks during the first six months after surgery for evidence of infection and local recurrence, every three months for the following two years and then every six months. A CT scan of the chest was performed every three

months in the first year and then every six months to detect pulmonary metastases. A bone scan was performed every six months in the first year and then annually until the last follow-up.

The Ilizarov external fixator was removed after graft union. This was followed by protection of the limb in a below-knee brace for an additional four to six months.

Union of the graft proximally and distally was assessed according to Hsu et $\mathrm{al}^{7}$ with graft union defined as uninterrupted external bony borders between the fibular graft and the recipient bone in addition to obscured or absent osteotomy lines at both junctions.

We assessed graft hypertrophy by the system of de Boer and Wood, ${ }^{8}$ using a graft hypertrophy index $\mathrm{I}_{\mathrm{n}}$ as:

$$
\left.\mathrm{I}_{\mathrm{n}}=\underline{\left(\mathrm{G}_{2}\right.} \underline{\underline{\mathrm{R}_{2}}} \underset{\left(\overline{\mathrm{G}}_{1}\right)-\left(\mathrm{G}_{1}\right)}{1} \underline{\mathrm{R}}_{1}\right) \times 100 \%
$$

where $G_{1}$ is the graft diameter at the proximal junction at operation, $\mathrm{R}_{1}$ is the host bone diameter at the proximal junction at operation, $G_{2}$ is the graft diameter at the proximal junction at follow-up and $\mathrm{R}_{2}$ is the host bone diameter at the proximal junction at follow-up.

The most recent follow-up was used for this index. A positive index value confirms hypertrophy and a negative value represents graft atrophy. We recorded hypertrophy only if the graft index had increased by more than $20 \%$.

The functional evaluation was performed using a modified system of the Musculoskeletal Tumour Society, ${ }^{5}$ which is based on six parameters: pain, functional activities, emotional acceptance, the use of external support, walking ability and gait.

\section{Results}

The mean post-operative functional score was 70\% $(63 \%$ to $73 \%$ ). Table I shows the details of the functional results. 

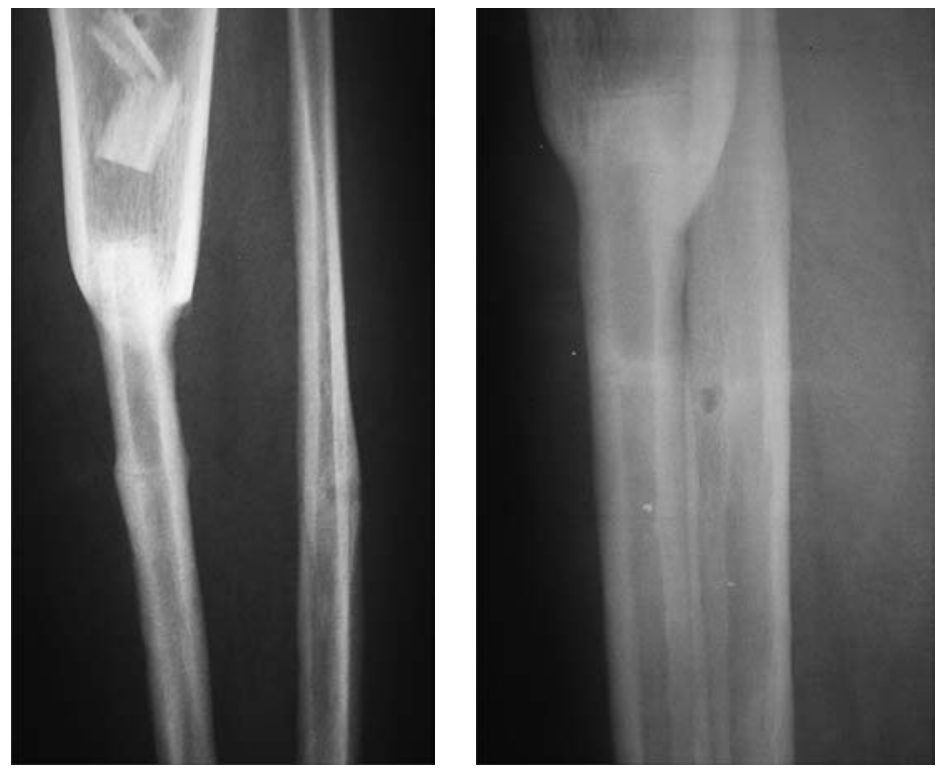

Fig. 3

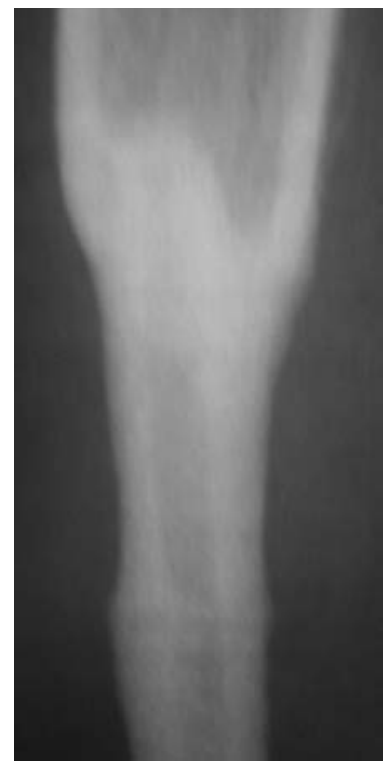

Full union of the graft and a hypertrophy index of $40 \%$ at the 42 -month follow-up.

Table I. Details of the functional results

\begin{tabular}{|c|c|c|c|c|c|c|c|}
\hline Patient number & Pain & Functional activities & Emotional acceptance & External support & Walking ability & Gait & $\begin{array}{l}\text { Total functional } \\
\text { score }(\%)\end{array}$ \\
\hline 1 & 4 & 3 & 5 & 3 & 3 & 3 & 70 \\
\hline 2 & 4 & 3 & 4 & 3 & 3 & 2 & 63 \\
\hline 4 & 5 & 3 & 5 & 3 & 3 & 3 & 73 \\
\hline 5 & 4 & 3 & 5 & 3 & 3 & 3 & 70 \\
\hline 6 & 5 & 3 & 5 & 3 & 3 & 3 & 73 \\
\hline
\end{tabular}

Five patients had good joint stability after sound fusion. Two patients required secondary iliac crest cancellous bone grafting at the proximal end to achieve union. The mean time to graft union was ten months ( 8 to 12 ) in patients with vascularised fibular grafts and 18 months (16 to 20$)$ in those with a free non-vascularised graft

All the patients showed graft hypertrophy at final followup with the exception of one patient who suffered a local recurrence. We believe that graft hypertrophy is a function of the mechanical stimulation of early weight-bearing permitted by the Ilizarov external fixator (Fig. 3). Table II sum- marises the details of the study group including complications, follow-up and results.

None of the patients had developed clinical signs or symptoms of arthritis of the mid-foot or the subtalar joints at their final follow-up.

Complications. A local recurrence occurred in one female patient one year post-operatively. This patient showed a poor response to pre-operative chemotherapy (grade II according to Huvos grading ${ }^{6}$ ) and was not compliant with the post-operative chemotherapy regimen. Subsequently she was treated by above-knee amputation and showed no

Table II. Details of this study group

\begin{tabular}{|c|c|c|c|c|c|c|c|}
\hline $\begin{array}{l}\text { Patient } \\
\text { number }\end{array}$ & $\begin{array}{l}\text { Type of fibular } \\
\text { graft }\end{array}$ & $\begin{array}{l}\text { Length of defect after } \\
\text { resection }(\mathrm{cm})\end{array}$ & $\begin{array}{l}\text { Length of fibular } \\
\text { graft }(\mathrm{cm})\end{array}$ & $\begin{array}{l}\text { Follow-up period } \\
\text { (mths) }\end{array}$ & Complications & $\begin{array}{l}\text { Time to graft } \\
\text { union (mths) }\end{array}$ & $\begin{array}{l}\text { Graft hypertrophy } \\
\text { index }(\%)\end{array}$ \\
\hline 1 & Non-vascularised & 19 & 22 & 42 & None & 16 & 40 \\
\hline 2 & Non-vascularised & 18 & 22 & 31 & $\begin{array}{l}\text { Stress fracture of } \\
\text { fibular graft }\end{array}$ & 20 & 25 \\
\hline 3 & Non-vascularised & 16 & 19 & 36 & Local recurrence & --- & --- \\
\hline 4 & Vascularised & 18 & 20 & 33 & Pin track infection & 8 & 40 \\
\hline 5 & Vascularised & 15 & 18 & 28 & None & 10 & 50 \\
\hline 6 & Vascularised & 16 & 18 & 40 & None & 12 & 50 \\
\hline
\end{tabular}


local recurrence or pulmonary metastases at one year after amputation.

One patient had a stress fracture at the proximal end of the non-vascularised fibular graft six months postoperatively. The graft was $22 \mathrm{~cm}$ long and the defect after tumour resection was $18 \mathrm{~cm}$. The patient was treated by application of autogenous iliac cancellous graft at the site of the fracture, and full union of the graft occurred after 20 months.

Pin track infection occurred in one patient and was treated by oral antibiotics and routine cleaning of the wire sites.

At the final follow-up the fusion was solid without any evidence of local recurrence or deep infection in five patients.

\section{Discussion}

Reconstruction after massive bone loss around the ankle is difficult because of the limited surrounding soft tissue and problems achieving adequate fixation. Accordingly, belowknee amputation has been the standard surgical procedure for malignant bone tumours involving the distal tibia, providing satisfactory function with a below-knee prosthesis. ${ }^{9}$

In spite of the fact that functional scores of a below-knee amputee are likely to be $90 \%$ or more, some patients refuse amputation for psychological or social reasons. ${ }^{10}$

Advances in chemotherapy have also made limb salvage surgery of the distal tibia increasingly possible. ${ }^{11}$ Limb salvage surgery consists of two main parts; en bloc resection of the tumour, and subsequent skeletal reconstruction. Various techniques have been described for reconstruction including endoprosthetic replacement, osteoarticular allograft, autograft, distraction osteogenesis or re-implantation of the tumour-bearing bone segment after devitalisation of the tumour cells by heating (autoclaving, pasteurisation and microwave-induced hyperthermia), freezing (using liquid nitrogen) or extracorporeal irradiation. ${ }^{12}$

Ankle endoprosthetic replacement has occasionally been carried out in patients with distal tibial tumours with a report of many complications and high rates of failure. ${ }^{11}$ Other reports also show a deterioration of functional outcome with time, together with significant medium-term morbidity. ${ }^{2,13}$

Among the many options of reconstruction, arthrodesis was regarded as the best, providing excellent stability of the ankle and avoiding problems relating to the prosthetic implantation. ${ }^{11}$ Casadei et $\mathrm{al}^{4}$ reported good functional and oncological results in patients with malignant bone tumours of the distal tibia, treated by resection and arthrodesis with autogenous bone graft.

The autogenous fibular graft has some important advantages over other donor sites because of its length, geometrical shape and mechanical strength. The fibula is a long and straight tubular bone which is not difficult to harvest. The anatomy is predictable and its size and shape allow tibial intramedullary insertion. Donor site morbidity has been reported as minimal with grafts up to $20 \mathrm{~cm}$ long. ${ }^{14}$

Non-vascularised autogenous fibular grafts hypertrophy, but only after they have been revascularised and repaired completely. Vascularised bone graft does not have to undergo creeping substitution and does not depend on the quality of the host bed for its success. In contrast, nonvascularised bone grafts need good vascularity of the host bed. $^{7}$

However, achieving stability after using fibular graft for reconstruction is difficult. The use of internal fixation carries a high rate of failure with infection being a disastrous complication. These techniques also involve long periods of non-weight-bearing which is a particular concern for tumour patients. ${ }^{15}$

Bishop et $\mathrm{al}^{3}$ achieved success with a reconstruction using a vascularised free fibular graft for the treatment of malignant tumours in the distal tibia. A successful fusion was obtained in nine of 11 patients.

Our technique has several advantages. The fibular strut graft is easy to harvest and causes minimal donor-site morbidity. It can also fit snugly inside the medullary canal of the tibia. The Ilizarov external fixator allows stability and longitudinal compression to be established early in the post-operative period, avoiding the problems of internal fixation of the fibular graft, enhancing graft hypertrophy and allowing early weight-bearing.

The vascularised fibula was superior to the nonvascularised graft with reduced time to union and faster hypertrophy.

The functional outcome was better than reconstruction with an endoprosthesis ${ }^{13}$ and more long-lasting. ${ }^{2}$ It was also comparable with that reported for below-knee amputation. ${ }^{10}$

We believe that wide en bloc resection arthrodesis, with reconstruction of the defect by autogenous fibular graft and fixation using an Ilizarov external fixator, together with pre- and post-operative chemotherapy, offers an effective alternative protocol for limb salvage in cases of osteosarcoma of the distal tibia.

This technique could be similarly applied to defect reconstructure after a wide range of bone pathologies which involve the distal tibia.

No benefits in any form have been received or will be received from a commercial party related directly or indirectly to the subject of this article.

\section{References}

1. Zeytoonjian T, Mankin HJ, Gebhardt MC, Hornicek FJ. Distal lower extremity sarcomas: frequency of occurrence and patient survival rate. Foot Ankle Int 2004;25:325-30.

2. Abudu A, Grimer RJ, Tillman RM, Carter SR. Endoprosthetic replacement of the distal tibia and ankle joint for aggressive bone tumours. Int Orthop 1999;23:291-4.

3. Bishop AT, Wood MB, Sheetz KK. Arthrodesis of the ankle with a free vascularized autogenous bone graft: reconstruction of segmental loss of bone secondary to osteomyelitis, tumor, or trauma. J Bone Joint Surg [Am] 1995;77-A:1867-75.

4. Casadei R, Ruggieri P, Giuseppe T, Biagini R, Mercuri M. Ankle resection arthrodesis in patients with bone tumors. Foot Ankle Int 1994;15:242-9. 
5. Enneking WF, Dunham W, Gebhardt MC, Malawar M, Pritchard DJ. A system for the functional evaluation of reconstructive procedures after surgical treatment of tumors of the musculoskeletal system. Clin Orthop 1993;286:241-6.

6. Huvos AG. Osteogenic sarcoma of bones and soft tissues in older persons: a clinicopathologic analysis of 117 patients older than 60 years. Cancer 1986;57:1442-9.

7. Hsu RW, Wood MB, Sim FH, Chao EY. Free vascularised fibular grafting for reconstruction after tumour resection. J Bone Joint Surg [Br] 1997;79-B:36-42.

8. de Boer HH, Wood MB. Bone changes in the vascularised fibular graft. J Bone Joint Surg $[\mathrm{Br}]$ 1989;71-B:374-8.

9. Simon MA. Limb salvage for osteosarcoma. J Bone Joint Surg [Am]1988;70-A:307-10.

10. Davis AM, Devlin M, Griffin AM, Wunder JS, Bell RS. Functional outcome in amputation versus limb sparing of patients with lower extremity sarcoma: a matched case-control study. Arch Phys Med Rehabil 1999;80:615-18.
11. Lee SH, Kim HS, Park YB, Rhie TY, Lee HK. Prosthetic reconstruction for tumours of the distal tibia and fibula. J Bone Joint Surg [Br] 1999;81-B:803-7.

12. Choong PF, Sim FH. Limb-sparing surgery for bone tumours: new developments. Semin Surg Oncol 1997;13:64-9

13. Natarajan MV, Annamalai K, Williams S, Selvaraj R, Rajagopal TS. Limb salvage in distal tibial osteosarcoma using a custom mega prosthesis. Int Orthop 2000;24:282-4.

14. Imran Y, Zulmi W, Halim AS. Skeletal union following long bone reconstruction using vascularised fibula graft. Singapore Med J 2003;44:286-7.

15. Bach AD, Kopp J, Stark GB, Horch RE. The versatility of the free osteocutaneous fibula flap in the reconstruction of extremities after sarcoma resection. World J Surg Oncol 2004:2:22. 